\title{
A nonhypnotic failure to replicate mood-dependent recall
}

\author{
TIMOTHY L. JOHNSON and ERIC KLINGER \\ University of Minnesota, Morris, Minnesota
}

\begin{abstract}
Subjects' moods of accomplishment or frustration were induced nonhypnotically by varying their goals on a pursuit rotor task. Immediately after mood induction, subjects learned a word list. After a second mood induction, subjects learned a second word list. Later they were asked to recall both word lists after a third mood induction. The results showed that moods were manipulated significantly, but subjects' recall performance was not significantly related to the match or mismatch of their learning and recall moods. Thus, recall was not mood-dependent.
\end{abstract}

Recall is considered to be "mood-dependent if it varies according to the similarity between the subject's mood at learning and at retrieval"' (Bower \& Mayer, 1985, p. 39). Initial attempts to demonstrate mood-dependent recall (MDR) employed a one-list design in which subjects learned a list of words while in a particular mood (e.g., happy or sad), and later tried to recall the list while in the same or opposite mood. Two such investigations (Bower, Monteiro, \& Gilligan, 1978, Experiments 1 and 2; Isen, Shalker, Clark, \& Karp, 1978) found no MDR effect, and two others (Leight \& Ellis, 1981, Experiment 2; Macht, Spear, \& Levis, 1977) found only partial or asymmetric MDR.

However, some investigations using a two-list interference design have successfully demonstrated MDR (Bartlett, Burleson, \& Santrock, 1982; Bower et al., 1978, Experiment 3; Schare, Lisman, \& Spear, 1984). In this design, subjects learned two separate word lists. The first list was learned while subjects were in a particular Mood A. The second list was learned while subjects were in the same Mood A or in a different Mood B. Later, subjects tried to recall the two lists while in one of the two moods. This resulted in the following conditions: ABA, $\mathrm{AAA}$, and ABB. Results were that the recall percentage of words was significantly higher when the learning and testing moods matched rather than when they mismatched. Bower (1981) attributed these results to interference.

Recently, Bower and Mayer (1985) attempted to replicate MDR in a two-list interference design, as reported earlier in Experiment 3 of Bower et al. (1978). However, their attempt failed. Because these experiments used hypnosis to induce mood states, Bower and Mayer (1985, p. 41) suggested that this failure "might be attributed to the hypnotic skills of the subjects and their relationship to the experimenter-hypnotist." Bower and Mayer pointed out that this suggestion would restrict the demonstration of MDR to special narrow subject populations and social

Requests for reprints should be sent to Eric Klinger, Division of Social Sciences, University of Minnesota, Morris, MN 56267. of MDR to special narrow subject populations and social situations. However, the positive findings of MDR by Bartlett et al. (1982) and Schare et al. (1984), who used different subject populations and mood-inducing methods, suggest the applicability of MDR to broader populations and situations. Moreover, MDR is conceptually linked to mood-congruent recall (i.e., better recall of material when its affective tone is congruent with the person's current mood), which, despite difficulties (e.g., Hasher, Rose, Zacks, Sanft, \& Doren, 1985), has been convincingly demonstrated (Bower, 1981; Ellis, Thomas, McFarland, \& Lane, 1985; Ingram, 1986; Rholes, Riskind, \& Lane, 1987; Snyder \& White, 1982; Teasdale \& Fogarty, 1979).

Inducing mood states through the use of hypnosis may introduce difficulties. First, since hypnosis heightens subjects' suggestibility, there is a greater chance that subjects will conform to demand characteristics by reporting the appropriate mood states and confirming the experimental hypothesis. The second difficulty is that subjects' cognitive interpretation of the hypnotic procedure may alter their experience of their emotional arousal. Mandler's (1975) and Schachter's (1971) two-factor theories of emotion hold that the cognitive interpretation of arousal "affects the quality and category of the [emotional] experience'” (Mandler, 1975, p. 67). This suggests a major problem if hypnotized subjects were to attribute their arousal to the hypnotic process. In the experiments of Dienstbier and Munter (1971) and Storms and Nisbett (1970), subjects who attributed their arousal to a placebo pill apparently experienced their arousal differently from those who had no explanation of their arousal. Also, Schachter (1971) found that in those conditions in which subjects had an explanation of their arousal (i.e., they were injected with epinephrine), subjects did not label their "state" in terms of the alternative cognitions available to them. These subjects "proved relatively immune to any effects of the manipulated cognitions" (Schachter, 1971 , p. 23). Thus, hypnotized subjects who attribute their arousal to the hypnotic process may become immune to the manipulated cognitions of hypnosis. Therefore, the 
problems of demand characteristics and unplanned cognitive interpretations would seem to weaken the case for hypnosis as a method for experimental mood induction.

In view of these considerations, we attempted a partial replication of Bower and Mayer's (1985) experiment, with the major difference that we induced mood states through the use of a goal-directed task (rotary pursuit) rather than through hypnosis. Without a ready basis for alternative attributions, we expected these subjects to attribute their moods to accomplishment (achieving a preset goal) or frustration (falling short of the goal). This method of mood induction carries the additional advantage over hypnotic induction that it can be used with most subject populations.

\section{METHOD}

\section{Subjects}

Fifty students in introductory psychology and geology classes volunteered to receive extra course credit for their participation, which took about $60 \mathrm{~min}$. Of the 50,8 were eliminated: 5 for achieving the timeon-target (TOT) goal during a frustration treatment (see below), 1 for not achieving the TOT goal during an accomplishment treatment, and 2 for their verbalized suspicions regarding the purpose of the pursuit rotor task. Of the remaining 42 ( 21 women, 21 men), 7 subjects were randomly assigned to each of six conditions, with sex of subject proportional across cells.

\section{Apparatus and Materials}

The subjects were permitted to use either hand to track a $3 / 4$-in. diameter disc on a Bogen MOD B-61 pursuit rotor with a speed of $16 \mathrm{rpm}$ and $45 \mathrm{rpm}$. An easily observable timer displayed their time on target (TOT). A Grayson-Stadler MOD 901-B noise generator sounded a white noise of $80 \mathrm{db}$ (SPL, as measured by a Bruel \& Kjaer Model 2203 soundlevel meter) when the stylus was not in contact with the target. The rotor automatically stopped after running for approximately $21 \mathrm{sec}$, which constituted one trial.

The Differential Emotions Scale IV (DES-IV) was adapted to measure mood states. The DES-IV is a 47-item, self-report measure of interest, enjoyment, surprise, sadness, anger, disgust, contempt, fear, shame, shyness, guilt, and self-directed hostility. It is a slightly refined DES-III (Izard, 1979), with added scales for shame and self-directed hostility. The subjects additionally used a brief global scale to rate the intensity of feeling pleased and frustrated.

The words to be learned were 32 nouns with concreteness ratings of less than 3.0 on a 7-point scale (Paivio, Yuille, \& Madigan, 1968). Sixteen words were assigned to each of the first and second lists, whose order during learning was counterbalanced across subjects and treatments.

A Califone 3430 tape recorder was used to play the word lists.

\section{Design}

Each subject was assigned to one of six conditions-each a mood treatment sequence-which fell into three condition pairs. The first condition pair contained the sequences AAA and FFF, where A represents accomplishment and $\mathrm{F}$ represents frustration. The subjects in this condition pair learned both word lists under the same mood and recalled them under the same mood. The second condition pair contained sequences AFA and FAF; the subjects learned the two word lists under opposite moods and recalled them under the first mood. The third condition pair contained sequences AFF and FAA, in which subjects learned the two word lists under opposite moods but recalled them under the second mood. Half the subjects in each condition started with moods of accomplishment and half with moods of frustration.

\section{Procedure}

The subjects were tested individually in a small room without distractions. Moods were induced by setting the pursuit rotor at a speed of $16 \mathrm{rpm}$ for accomplishment and $45 \mathrm{rpm}$ for frustration. The experimenter demonstrated the rotor whenever a subject was to experience a speed for the first time. Before an accomplishment treatment (rotor set at $16 \mathrm{rpm}$ ), the rotor was demonstrated for only part of a $21-\mathrm{sec}$ trial, so that the subject could not compare his/her TOT unfavorably with the skilled experimenter's TOT. However, before a frustration treatment (rotor set at $45 \mathrm{rpm}$ ), the rotor was demonstrated for the whole 21-sec trial, so that the subject might compare his/her TOT with the experimenter's average TOT of $17 \mathrm{sec}$. After the demonstration, the subject was told, "For this part of the experiment, it is important that you hold the stylus on the target for at least" $18 \mathrm{sec}$ (with the rotor set at $16 \mathrm{rpm}$ ) or $14 \mathrm{sec}$ (with the rotor at $45 \mathrm{rpm}$ ). A pilot experiment revealed that a TOT of $18 \mathrm{sec}$ was easily achieved at $16 \mathrm{rpm}$, and a TOT of $14 \mathrm{sec}$ was hardly ever achieved at $45 \mathrm{rpm}$. Each subject then performed $1021-\mathrm{sec}$ trials and was permitted short rest periods between trials whenever he/she requested.

After an accomplishment treatment, the subject received verbal compliments, such as "You're doing well!" "You're really consistent!" and "Good job!" After a frustration treatment, the subject received uncomplimentary statements, such as "You're really having trouble with this" and "You make it look hard." These latter subjects were often reminded of the goal and the number of trials left to reach the goal.

After inducing the first mood, a tape recorder played the first word list aloud twice, in a different random order each time, at $3 \mathrm{sec}$ per word. The subject was then given $2 \mathrm{~min}$ to recall orally as many of the words as he/she could in any order. After recall, the list was played in a random order for a third time, and the subject had another $2 \mathrm{~min}$ for oral free recall. This recall constituted the criterion for original learning. The subject was then told that this part of the experiment was over and he/she would be starting a new part of the experiment. The second mood was then induced, and the same procedure was repeated for the second word list.

After learning and recalling both word lists, the subject was given $10 \mathrm{~min}$ in which to take a short break and write general information about himself/herself (which served as a filler and distractor task). After the $10 \mathrm{~min}$, the third and final mood was induced, after which the subject had $3 \mathrm{~min}$ to recall orally the first word list and an additional $3 \mathrm{~min}$ to recall the second word list. Immediately afterward, the subject filled out the brief global measure of the intensity with which he/she felt pleased and frustrated, as well as the Differential Emotions Scale IV (DES-IV). The experimenter then asked the subject what he/she thought the purpose of the experiment was and debriefed the subject.

\section{RESULTS}

\section{Mood Manipulations}

A pilot experiment showed that the pursuit rotor task did affect the subjects' moods. The subjects rated their mood intensities on 5-point scales $(1=$ not at all, $5=$ very strongly) immediately after performing the pursuit rotor task for 10 trials. Using the enjoyment category of DES-IV, the 7 subjects in the accomplishment treatment reported feeling more joy $(M=4.09, S D=.81)$ than the 7 subjects in the frustration treatment $(M=1.67$, $S D=.61$ ). These differences and those of the mood comparisons reported below were tested by means of $t$ tests for correlated data, with all reported differences significant beyond the .0001 level.

In the present experiment, the subjects reported the intensity of moods (on a 5-point scale as above) after the final recall period. The joy category on DES-IV showed that the 21 subjects who ended in accomplishment reported more enjoyment $(M=3.89, S D=.81)$ than the 21 subjects ending in frustration $(M=2.33, S D=.79)$. On the brief measure of moods, the subjects ending in accomplishment also reported feeling more pleased $(M=4.05, S D=.80)$ and less frustrated $(M=1.67$, 
$S D=.86)$ than those ending in frustration $(M=2.19$, $S D=.95$, and $M=3.33, S D=.86$, respectively).

Mood sequences ending in the same mood state did not differ significantly by analysis of variance (ANOVA) on joy, pleasure, or frustration variables $(p>.05)$. Also, the overall original recall for the two word sets did not differ significantly $(M \mathrm{~s}=12.69$ and 13.02).

\section{Mood-Dependent Recall}

Table 1 reports mean recall percentages of the two word lists. Recall percentage is the final recall of words for a given list (after learning both lists) divided by the number of words recalled after original learning of that list.

For mood sequences that start with an accomplishment treatment, MDR occurs when subjects in sequences AFA and AAA recall more of List 1 than subjects in the AFF sequence. The mean recall percentages obtained (Table 1) fell in the predicted order, but did not differ significantly across the three sequences $[F(2,18)=0.82, p<.46]$. Referring to List 2, MDR occurs when subjects in the AFF condition recall more of the list than subjects in the AFA and AAA sequences. Again, mean recall percentages did not differ significantly $[F(2,18)=0.58$, $p<.57]$.

For mood sequences beginning with a frustration treatment, MDR occurs when subjects in sequences FAF and FFF recall more of List 1 than subjects in the FAA sequence. As Table 1 shows, the mean recall percentages apparently fell in the opposite order, but did not differ significantly $[F(2,18)=1.88, p<.18]$. Mean recall percentages for List 2 also did not differ significantly $[F(2,18)$ $=0.05, p<.96]$. Thus, there was no MDR effect.

\section{Influence of Mood on Learning and Recall}

A mood at learning (accomplishment vs. frustration) $\times$ list learned (first vs. second) ANOVA showed no significant influence of mood on learning performance. A recall mood $\times$ list recalled $\times$ learning mood ANOVA did not show any significant effect on recall percentage (as described above).

\section{DISCUSSION}

The goal of this experiment was to use a mood induction method that did not restrict mood-dependent recall to as specific a subject population or as narrow a class of social situations as does hypnosis. The results indicated that mood states were successfully manipulated: mood intensities did not differ for sequences ending in the same mood state, but did differ for sequences ending in an opposite mood state. However, these conditions did not produce MDR

The absence of mood-dependent recall in this experiment contradicts our beginning assumption that a nonhypnotic method of mood induction would facilitate finding MDR. There are two possible methodological explanations. First, since mood intensities in the experiment were not measured after each learning phase, but only at the end of all three phases, it is possible that mood intensities within the same repeated treatment (e.g., frustration) differed enough to block MDR. Second, the subjects' varying degrees of success in the word learning task may have induced enough of their own feelings of accomplishment or frustration to override the mood induction produced by the rotary pursuit treatments.

Perhaps MDR is too complex or subtle an effect for the experimental designs used to date to demonstrate reliably. For example, using hyp-
Table 1

Mean and Standard Deviations for Recall Percentages as a Function of Mood Sequence and Word List

\begin{tabular}{cccccc} 
& \multicolumn{4}{c}{ List } \\
\cline { 2 - 5 } Sequence & $M$ & $S D$ & & \multicolumn{2}{c}{ Two } \\
\cline { 2 - 5 } & \multicolumn{2}{c}{ One } & .09 & .85 & .21 \\
AFA & .50 & .21 & .75 & .22 \\
AAA & .43 & .17 & .76 & .12 \\
AFF & .39 & .44 & .20 & .84 & .26 \\
FAF & .44 & .16 & .85 & .16 \\
FFF & .59 & .28 & .88 & .28 \\
FAA & .67 & .28 &
\end{tabular}

Note $-\mathrm{A}=$ accomplishment. $\mathrm{F}=$ frustration.

notic mood induction, Bower and Mayer (1985) failed to replicate their earlier finding of MDR (Bower et al., 1978, Experiment 3). Using nonhypnotic mood induction, we did not find MDR in the present experiment, whereas Bartlett et al. (1982) and Schare et al. (1984) did in their experiments. All these experiments used word list recall as the dependent variable. Perhaps mood-dependent recall occurs more reliably when actual life events are used as the dependent variable. Although Bower (1981) reported findings that support this view, the possibility requires further investigation.

In conclusion, either MDR is too complex or subtle a phenomenon to produce reliably in the laboratory or more creative methods need to be formulated-or it does not exist.

\section{REFERENCES}

Bartlett, J. C., Burleson, G., \& Santrock, J. W. (1982). Emotional mood and memory in children. Journal of Experimental Child Psychology, 34, 59-76.

Bower, G. H. (1981). Mood and memory. American Psychologist, 36, 129-148.

Bower, G. H., \& MAYER, J. D. (1985). Failure to replicate mooddependent retrieval. Bulletin of the Psychonomic Society, 23, 39-42.

Bower, G. H., Monteiro, K. P., \& Gilligan, S. G. (1978). Emotional mood as a context for learning and recall. Journal of Verbal Learning \& Verbal Behavior, 17, 573-585.

Dienstbier, R. A., \& Munter, P. O. (1971). Cheating as a function of the labeling of natural arousal. Journal of Personality \& Social Psychology, 17, 208-213.

Ellis, H. C., Thomas, R. L., McFarland, A. D., \& Lane, J. W. (1985). Emotional mood states and retrieval in episodic memory. Journal of Experimental Psychology: Learning, Memory, \& Cognition, 11, 363-370.

Hasher, L., Rose, K. C., Zacks, R. T., Sanft, H., \& Doren, B. (1985). Mood, recall, and selectivity effects in normal college students. Journal of Experimental Psychology: General, 114, 104-118.

Ingram, R. E. (1986, August). Processing of depressive and anxious information by depressed and anxious individuals. Paper presented at the annual meeting of the American Psychological Association, Washington, DC.

Isen, A. M., Shalker, T., Clark, M., \& KarP, L. (1978). Positive affect, accessibility of material in memory, and behavior: A cognitive loop? Journal of Personality \& Social Psychology, 36, 1-12.

IZARD, C. E. (1979). The differential emotions scale for children (DESIII). Unpublished manuscript, University of Deleware.

Leight, K. A., \& Ellis, H. C. (1981). Emotional mood states, strategies, and state-dependency in memory. Journal of Verbal Learning \& Verbal Behavior, 20, 251-266.

Macht, M. L., SPEar, N. E., \& Levis, D. J. (1977). State-dependent retention in humans induced by alterations in affective state. Bulletin of the Psychonomic Society, 10, 415-418.

Mandler, G. (1975). Mind and emotion. New York: Wiley.

Paivio, A., Yuille, J. C., \& Madigan, S. A. (1968). Concreteness, imagery, and meaningfulness values of 925 nouns. Journal of Experimental Psychology Monographs, 76(1, Pt. 2). 
RHoles, W. S., Riskind, J. H., \& LANE, J. W. (1987). Emotional states and memory biases: Effects of cognitive priming and mood. Journal of Personality \& Social Psychology, 52, 91-99.

Schachter, S. (1971). Emotion, obesity, and crime. New York: Academic Press.

Schare, M. L., Lisman, S. A., \& Spear, N. E. (1984). The effects of mood variation on state-dependent retention. Cognitive Therapy \& Research, 8, 387-407.

SNyder, M., \& White, P. (1982). Moods and memories: Elation, depression, and the remembering of the events of one's life. Journal of Personality, 50, 149-167.

Storms, M. D., \& NisbetT, R. E. (1970). Insomnia and the attribution process. Journal of Personality \& Social Psychology, 16, 319-328.

Teasdale, J. D., \& FogarTY, S. J. (1979). Differential effects of individual mood on the retrieval of pleasant and unpleasant events from episodic memory. Journal of Abnormal Psychology, 88, 248-257.

(Manuscript received for publication October 24, 1987.) 